\title{
Understanding breast cancer screening: should the intellectually non-disabled make decisions for the intellectually disabled?
}

\author{
Dr. Ingrid Mühlhauser is professor of health sciences of the University Hamburg
}

In the USA, 70\% of women without a cervix have cervical cancer screening (Sirovich \& Welch 2004). According to a recent survey most individuals would overrule a physician who recommended against cancer screening, $60 \%$ want to be tested even for cancers that would never cause problems during the person's lifetime if untreated, and $40 \%$ believe that an 80-year old woman who chose not to have a screening mammogram was irresponsible (Schwartz et al. 2004). In another recent survey in the US, UK, Italy, and Switzerland widespread misconceptions about mammography screening were found: 60 to $70 \%$ of women believed that screening prevents or reduces the risk of contracting breast cancer and that screening at least halves breast cancer mortality (Domenighetti 2003). Evidence is overwhelming that understanding of cancer screening is poor among the intellectually non-disabled.

"All screening programmes do harm; some can do good as well. The harm from a screening programme starts immediately; the good takes longer to appear. Therefore, the first step of any programme, even an effective one, is to impair the health of the population." (Muir-Gray 1997) As to breast cancer screening the scientific controversy about the benefitharm ratio has not been resolved (Olsen \& Gøtzsche 2001). But, even if effective, breast cancer screening will benefit very few and many more will be harmed.

Under such circumstances informed decision making by the individual becomes an ethical issue. Criteria have been defined for consumer information on screening interventions (General Medical Council 1999). The information should be evidence-based. It should communicate prognosis without intervention, probability of benefit, risk of failure and harm, likelihood of positive and negative findings and possibility of false test results. Since framing of data has an important influence on risk perception results should be presented in natural frequencies (Hoffrage et al. 2000). The information must not be withheld because of the possibility that the person might refuse the screening test (General Medical Council 1999).

Information on breast cancer screening does not fulfil these criteria. The material is poor and severely biased in favour of screening (Slaytor \& Ward 1998; Jørgensen \& Gøtzsche 2004). Public health officials, physicians and disease advocacy groups use powerful campaigns to convince individuals of the importance of cancer screening. The messages are unbalanced, misleading and prescriptive (Schwartz et al. 2004). From a public health perspective screening programmes are cost effective only at high participation rates. Hence, increasing awareness and attendance rates are considered good practice whereas a woman who declines is a failure.

Sullivan et al. (2004) investigated why women with intellectual disabilities are among the least frequent users of mammography screening services. Barriers identified by carers included a need to motivate people to attend, the belief that women with intellectual disability would not understand why the procedure needs to be done and therefore would experience fear and anxiety, and severe medical problems.

Motivating women with learning disabilities to participate in breast cancer screening raises particular ethical concerns. A proactive and persuasive approach is not justified in case of preventive interventions that target healthy people and that may do more harm than good to the individual. Good practice guidelines on breast screening for women with learning disabilities have been issued (NHSBPS 2000). One

Soz.- Präventivmed. 49 (2004) 359-360

0303-8408/04/060359-2

DOI 10.1007/500038-004-4024-8

(c) Birkhäuser Verlag, Basel, 2004 
component is assessing capacity of the person to consent. However, understanding and interpretation of the person's views and wishes may be biased by the researchers' and carers' own beliefs and attitudes towards screening. Sullivan et al. give examples: Carers felt that their clients would see breast cancer as something that might not happen to them and concluded that their knowledge about breast cancer was "extremely limited to nil". An alternative interpretation could be that the understanding of breast cancer risk by these women is much closer to reality than the prevailing overestimation of breast cancer risk among the intellectually non-disabled. Women who feared that something could be found and they would become ill were classified as clients who misunderstood the concept of screening. Facing the evidence that mammography screening leads to substantial overdiagnosis and overtreatment (Olsen \& Gøtzsche 2001) the understanding of these women with intellectual disabilities appears quite appropriate and contrasts the misconceptions found in national surveys (Schwartz et al. 2004; Domenighetti et al. 2003).
Sullivan et al. (2004) have an important message. That is, that barriers to mammography screening would be difficult to overcome for most women with intellectual disablement. But, the suggested alternative to organise a system of clinical breast examination does not out-wit ethical issues. Clinical breast examination has not been rigorously studied and is equally controversial as mammography screening (Kösters \& Gøtzsche 2003). The British NHS explicitly advises against palpation of the breast by either medical or nursing staff as part of routine health screening of women, including those with learning disabilities (NHSBPS 2000). In the study by Sullivan et al. (2004) carers also reported about clients who were thought to understood what they were being asked but who refused to cooperate, "probably to assert their right of choice". Understanding of breast cancer screening among women with learning disabilities may be not be inferior to the understanding among the general population.

\section{References}

Domenighetti F, D'Avanzo B, Egger M, et al. (2003). Women's perception of the benefits of mammography screening: population-based survey in four countries. Internat J Epidemiol 32: 816-21.

General Medical Council (1999). Protecting patients, guiding doctors: seeking patients' consent: the ethical considerations. London: GMC. www.gmc-uk.org.

Hoffrage U, Lindsey S, Hertwig R, Gigerenzer $G$ (2000). Communicating statistical information. Science 290: 2261-2.

J $\phi$ rgensen KJ, Gøtzsche PC (2004). Presentation on websites of possible benefits and harms from screening for breast cancer: cross sectional study BMJ 328: 1-6 (online version).

Kösters JP, Gøtzsche PC (2003). Regular selfexamination or clinical examination for early detection of breast cancer (Cochrane Review). In: The Cochrane Library, Issue 3. Oxford: Update Software.
Muir-Gray JA (1997). Evidence-based healthcare. Edinburgh: Churchill Livingstone.

NHSBPS (2000). Good practice in breast and cervical screening for women with learning disabilities. Sheffield, NHS Cancer Screening Programmes. (NHSBSP publication no 46; NHSCSP no 13).

Olsen O, Gøtzsche PC (2001). Systematic review of screening for breast cancer with mammography (Cochrane Review). Cochrane Database Syst Rev 2001 and Lancet 2001. http://image.thelancet.com/lancet/extra/ fullreport.pdf.

Schwartz LM, Woloshin S, Fowler FJ, Welch HG (2004). Enthusiasm for cancer screening in the United States. JAMA 291: 71-8.

Sirovich BE, Welch AG (2004). Cervical cancer screening among women without a cervix. JAMA 291: 2990-3.

Slaytor EK, Ward JE (1998). How risks of breast cancer and the benefits of screening are communicated to women: analysis of 58 pamphlets. BMJ 317: 263-4.
Ingrid Mühlhauser
Sullivan SG, Slack-Smith LM, Hussain R (2004). Understanding the use of breast cancer screening services by women with intellectual disabilities. Soz Praventiv Med 49: 398-405.

Address for correspondence

Univ.-Prof. Dr. med. Ingrid Mühlhauser
Universität Hamburg, FB 13,
IGTW-Gesundheit
Martin-Luther-King Platz 6
D-20146 Hamburg
e-mail: Ingrid_Muehlhauser@uni-hamburg.de
Tel.: +49 40428383988
Fax: +49 40428383732
http://www.chemie.uni-hamburg.de/igtw/
Gesundheit/gesundheit.htm
http://www.gesundheit.uni-hamburg.de/

